\title{
The Role and Potential of Information Technology in Agricultural Development
}

\author{
Ramanna Havinal \\ Department of Electronics and Communication engineering \\ Maharaja Institute of Technology Mysore, India
}

\begin{abstract}
Rural people are migrating towards urban areas to search the better opportunities for last couple of decades. Basic infrastructure facilities available in rural area are very less. Due to the lack of development and opportunities rural community will migrate to urban areas in search of jobs. This causes decline in economy of rural areas. Special focus has to be given for rural development which can enhance economy, social status and life style and living standards of the rural people. The task is to find different ways of using the ICT to assist development in activity in rural to improve living standard and achieve a specific goal or objective Agriculture is one of the major components of economy and plays a key role in the nation development. But improvements in agricultural sector are uneven and disappointing. ICT has the potential to address the challenges, however use of the technology in agricultural and rural areas is very slow. Purpose of the proposed study is to review the opportunities, potential and contribution of ICT in agricultural sector
\end{abstract}

Keywords - Agriculture, information and communication technology,

\section{INTRODUCTION}

Since long farmers are facing and affected by many challenges such as adverse climate change, natural disasters loss of biodiversity, volatile food price, inefficient supply chains etc. Agricultural development is facing lot of challenges due to increased food demand, poverty and malnutrition reduction. Sustainable agricultural is required along with environment protection. The farmers have to make complex decisions on land usage, seeds selection, plants selection, market choice for the agro based products etc which will have an impact the livelihoods of their families and society[1].

Agriculture is the primary source of income for the rural population in most of the countries. This sector is facing many challenges to enhance production.ICT have a potential to meet the challenges faced by farmers and can enhance the living standard of rural community. Farmers are facing various problems and not getting fair prices to their agricultural products. The profit margin is very low because of hike in fertilizers, pesticides and fuel price. Agricultural development is slowed down by globalization and market fluctuation. ICT provides market access to the farmers. It provides an opportunity to increase the income. Also gives relevant information facilitating an environment for more remunerative agriculture ICT facility can be use to provide necessary information regarding new ways of farming, fishing, animal husbandry, etc.
However, despite of development and innovations in ICT technology its implementation in agriculture and rural community limited by illiteracy, Unaware of ICT facility, Non availability of relevant information in their regional or local; language, easy and affordable accessibility to ICT services[1]. ICT can be used a s a tool to solve problems and meet the challenges of rural community ICT facility, services can be used to minimize inequality, division between rural and urban community which will bring the transformation in rural areas and agricultural sector. The main focus of ICT in agriculture is to reduce the cost, increase of efficiency and productivity. The aim of the study is look for the potential solutions to reduce issues and digital divide among population in rural and urban areas This paper overviews the potential contribution of ICT to the agriculture.

\section{RURAL DEVELOPMENT}

Large number challenges and issues are to be resolved which are inhibiting the effective implementation of ICT in rural area and agricultural sector. There are three basic challenges in rural areas: access, quality, and cost[1].The rural areas in general often suffer from inadequate infrastructure such as electricity or water, communication, transportation etc. Also low literacy levels at most rural communities. Mobile connectivity and quality of service available in rural area is very poor compared to urban areas. The lack of electricity is the biggest problem to provide ICT services in rural areas. Most of the facilities and services are available in English which are not useful and suitable for rural community as they are familiar with verr

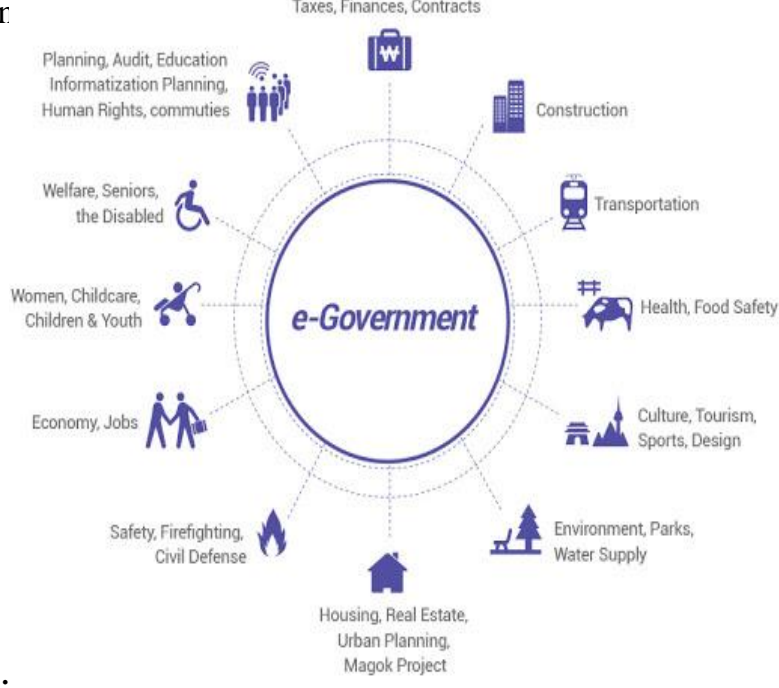

Figure 1 Components of e-government 
Majority of the development schemes are designed for urban area and neglected the peoples in rural and remote areas. It is necessary to develop plans which must be focused on rural lives. Due to lack of basic facilities, market linkages etc rural area people life is never easy compared to urban area. Rural community doesn't have the opportunities to participate in non farming activities which will improve their economy because of lack access to the tools. Rural community is always suffering from various external factors such as droughts, heavy rainfall, abnormal weather conditions on the crop yields, health facility etc. This pushed large number of families on the continent into poverty. Figure 1 shows the egovernment component

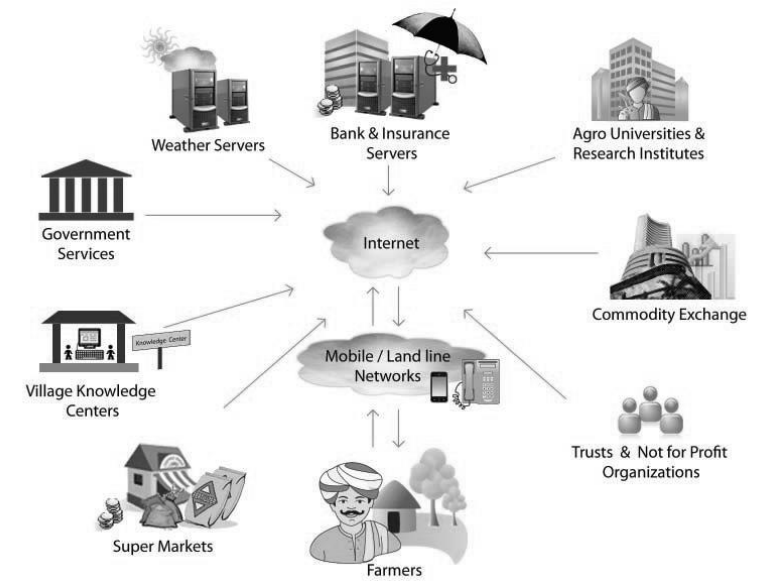

Figure 2 ICT services (courtesy: TCS)

Farmers need opportunities to participate in the global food market. This may bring economic independency and reduce risk and transaction costs. Roads, dams, ports, and irrigation are not sufficient for rural peoples, farmers also needs an enabling environment. Development in agriculture sector alone is not sufficient to change the life of rural peoples, but it also requires broad investment in non-farm activities, social services, governance, and finance, education, health,etc. Figure 2 shows the agricultural development strategy

However every sector has its own features, challenges, and opportunities. The potential applications of ICT in rural development could end the isolation of people living in poverty, disconnected from urban facilities and unable to participate fully in the global economy. Some of the development issues should be addressed together. Sustainability development can be achieved by focusing on three overlapping areas: demand, supply, and environment. We need to understand the rural populations, the more we realize better we can understand them. Knowing the end user one can design with the user requirements in mind. Innovations are required to know the behaviors or processes those are easier to adopt that can fill an existing gap.

\section{ICT IMP;LEMENTATION}

ICTs and traditional technique can be used concurrently to provide the information. Figure 3 shows agricultural development strategy

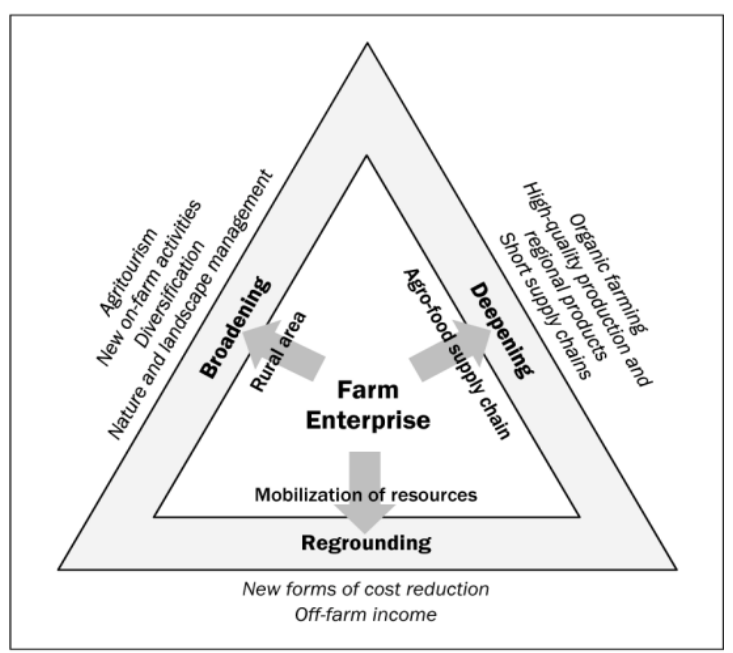

Figure 3 Agricultural development strategy (courtesy: DOI (10.5304/JAFSCD)

It cats as tools to optimize their production, marketing plans promote the expansion of local markets. It provides direct access for producers to international markets and productive resources. Figure 5 illustrates the ICT services in rural area.

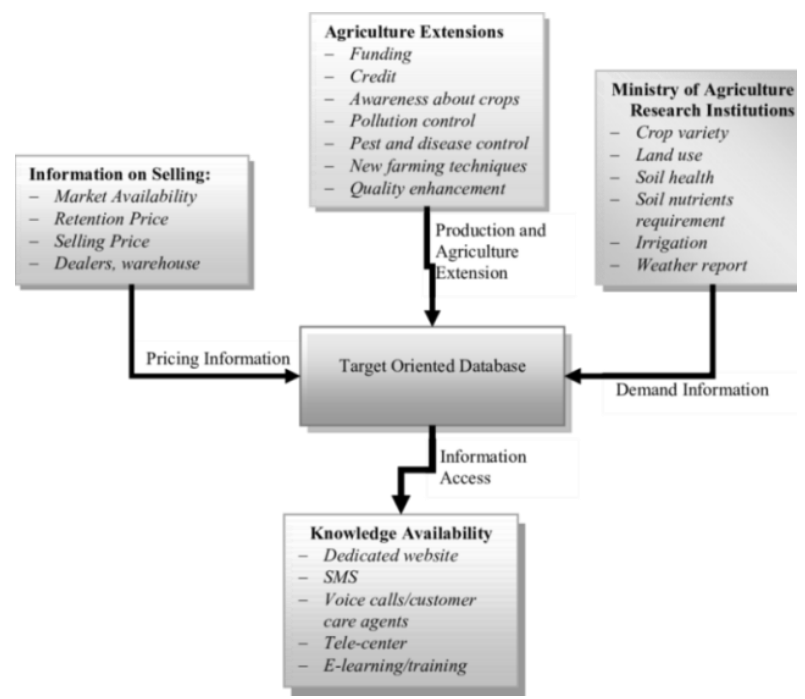

Figure 4 ICT service in rural area

ICT facilities can be used to promote the expansion of local markets. It can also be used to provide direct access to producers to international markets and productive resources Figure 4 ICT services in agriculture

The main focus of ICT in agriculture is to meet information need of the farmers and other rural community. They require access to ICT in their daily activities [2] e.g., Land records, registration, Helpline, best packages, postharvest information, agricultural news, crop insurance, adverse weather condition, farm business and management information, information about government schemes, market scenario, early warning of diseases and pests, dairy market conditions, finance, soil information

\section{ICT Impact}

Technological innovations are taking place at a rapid rate. Impacts of ICT on various sectors are needed to be measured. It is very difficult to determine which ICTs are worth supporting and which are not. It is essential develop enabling environment by providing suitable infrastructure, facilities, 
financial support and drafting of appropriate ICT policies and regulations. Figure 5 shows ICT usage[11] for rural youth

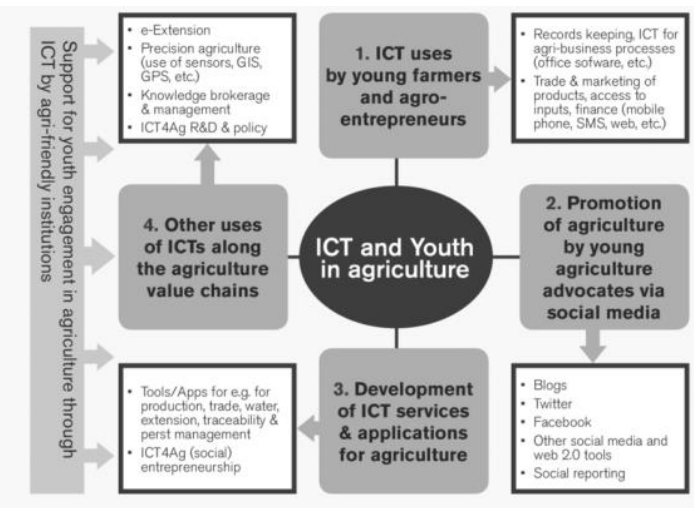

Figure 5: ICT usage for rural youth

Direct contribution[3]: ICT services can be used to obtain useful information on precise forming. weather conditions, agronomics and soil science, temperature of air and soil, rainfall, relative humidity of air, moisture of leaf, moisture of soil, length of day, speed of wind and solar radiation.

Indirect contribution: ICT supports the farmers in decision making and involve them in agriculture development. It helps the farmers stay competitive and survive on globalized market changes in the agricultural environment are necessary for the farmers. Internet helps farmers to track prices and communicate with others. ICT services facilitate rural peoples to exchange ideas and interact with each other to solve their problems. Farmers also receive information and guidance form experts regarding cultivation of crops and animals. It has reduced the gap between agricultural researchers and farmers.

Capacity-building and empowerment[3] ICTs will strengthen the capacities of the rural people and farmer to better represent in negotiating prices, land claims, resource rights and infrastructure etc. It provides a link to rural communities to interact with other stakeholders. ICT can make processes more efficient and transparent. Rural communities will get better access to credit and banking facilities with reduced cost through ICT services.

\section{ICT IN AGRICULTURE}

Over the past 50 years, crop yields have grown at very different rates. Small scale farming are much less productive and profitable because of lack of access to inputs, credit, inability to bear risks information and skills gap to adopt available technologies and management practices. Public extension programs are often underfunded, suffer from weak agricultural research and lack adequate contact to farmers. Another issue is the lack of coordination along the agricultural value chain from farm inputs to food processing, which increases the cost of production and lowers revenue for farmers. Farming is becoming a more time-critical and information-intense activity. A push towards higher productivity will require an information based decision making agricultural system. Farmers must be get information at the right time and place.

ICT services play a dominant role to improve agricultural production. Role of ICT in agricultural is shown in figure6. ICT can be used to solve food safety problems and enhance formers confidence. ICT cam strengthening the capacity of small-scale producers.GIS and Agro Meteorological Technologies features can be used for land-use planning, crop forecasting and early warning systems etc. Growing number threats from natural disasters can be monitored through space technology. Disease surveillance and pest tracking information can be obtained through mobile phones. It will also helps in providing solutions to the later stages of the agricultural value chain (e.g. post-harvest, transport, storage).

Need to understand agriculture process into a broader perspective and look at the agricultural activities within its economic, social and institutional environment.

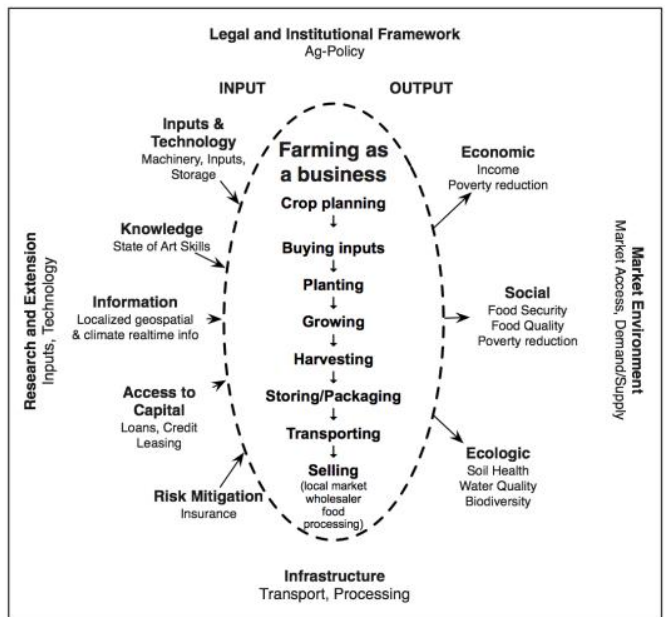

Figure 6 Broader perspective of agriculture [5]

We need to know the existing process and experiences as well as the impact of IC on productivity and performance of individual farmers, of the agrifood value chain, supporting services, and the agriculture sector as a whole (Figure 6).

Agriculture is the backbone for the majority of rural communities .ICT can be used to provide solution to challenges faced by the farmers.

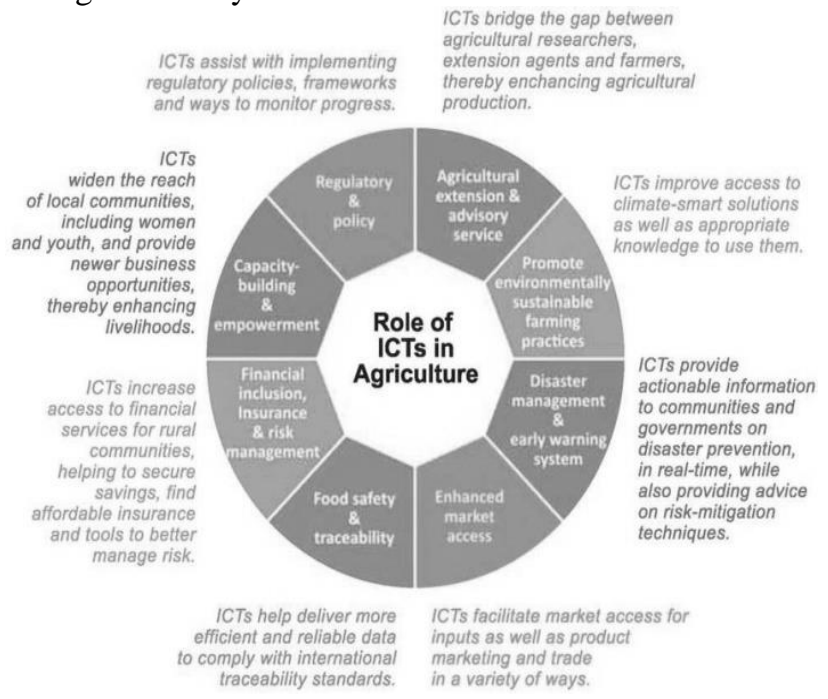

Figure 7: Role of ICT in agriculture[4] 
It provides information regarding climate change to minimize the effects of the unpredictable weather on agricultural production. Therefore, important factor provide access to the farmers on climate update. Role of ICT in Agriculture is shown [4] in figure 7 All ICT interventions in agricultural value chains help farmers to improve their productivity, yields and profitability in agricultural and allied activities. Some of the ICT enables services in agriculture and allied activities.

\section{Empowers the formers}

ICT provides the information of market trends and prices which helps the them to negotiate prices, protect their food security and livelihoods. Following areas [1] where ICT can be applied

Agricultural advisory: ICTs provides weather forecasts, crop specific advisory according to the stage in the crop cycle and price information, which empowers farmer and prepare them to utilize their resources profitably.

Financial services: Availability and access to timely and lowcost credit from banks is of great importance for sustainable and profitable farming. The banks facilities such as savings, credit, insurance and remittance can be accessed through smart cards..

Agricultural marketing: Various ICT platforms enhanced formers ability to the control production and manage supply chains. ICT platforms assist helps in making better decision regarding transportation and logistics, price and location, supply and demand and cheaper access to inputs.

Risk transfer: The ICT platform facilitate financial transactions, capturing data about crop loss and damage assessment will help in getting insurance claims

Way ahead: ICT provides a means to exchange of vital information between farmers and service providers Thus, ICT innovation empowers farmers by facilitating timely access to localized and personalized information.

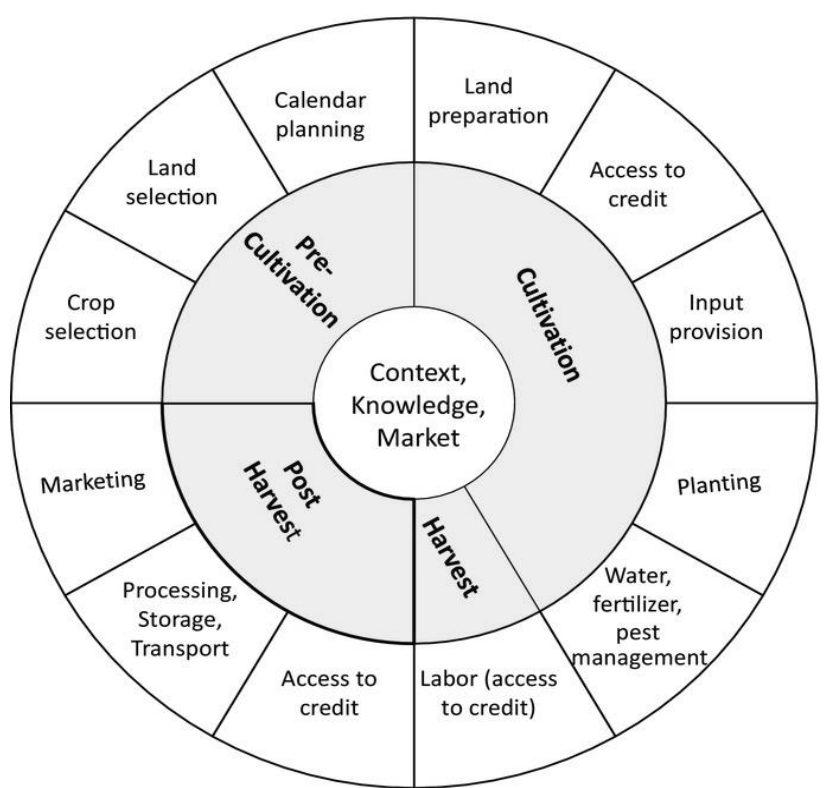

Figure 8 ICT for agricultural services [11]

ICT utilization in agriculture service is shown in figure 8 Farmers' needs necessary financial necessary services such as credit; savings; transfer\& payment facilities and; insurance achieve economic goals. The ICT can provide more diverse financial facilities and lower business and transaction costs. It will extend services of formal (i.e., banks) and semi-formal institutions (such as NGO Microfinance Institutions [MFIs] to reach to the rural community to meet primary needs

1. Land Management - Geographical Information System technology helps to manage their land resources effectively.

2. Livestock Management - Livestock is prime sources of food and capital that is available to rural peoples and they have to be protected. The GPS on livestock can be used to monitor movement and behavior while it feeds to detect any abnormalities

3. Plant Disease Detection - Early detection process is difficult to do manually, ICT technologies can assist in this process can starve off disaster.

4. Irrigation Management-Water is a precious resource which needs to be used properly. Agricultural activities require large quantities of water for irrigation. ICT function allows users to monitor soil moisture. The farmers can better irrigate their crops by obtaining information on regarding when to irrigate and the amount of water required etc which will reduce the water wastage. There is definitely gap exist between research and potential contribution of ICT in agriculture

\section{Farmers Requirement}

The main focus of ICT in agriculture is to meet the farmers' information needs [5]

1. Crops: Formers are interested to know about seeded crops, land size with specific crops, seed dropping time, harvest time, yields etc. They can make their own production plans based on the information.

2. Production techniques: Formers are willing to know the information prepared by agricultural institutes and other organizations to bring improvement in agricultural sector

3. Equipment and agricultural inputs: Farmers are interested to know equipment price of e.g production equipment for soil processing, seeds, pests and other agricultural inputs.

4. Market information: Farmers primary aim is to gain the best prices for their products by getting information on market for various agricultural products.

5. Other information: Farmers and their families require information such as weather forecast, financial facility, pests, early warning of diseases and advice on agricultural experts on crops etc. They also need supporting operative aspects of agricultural production which will help them in operative management of agricultural production in future.

6. Marketing information: farmers are interested to know the current market information regarding prices of agricultural commodities etc. 
7. Access to land records/ online registration: farmers need to access to land record and perform online registration for various government schemers

8. Question-and-answer service: need advice from experts on agriculture and animal husbandry, new technologies and advice on various problems.

9. Development programmes needs information about all government projects relating to rural development an subsidies.

10. Weather forecasting : needs to know information on rainfall, temperature and humidity

11. Packages of practices: needs to know information on 'best practices' for cultivating various crops despite the heavy rain or draught.

12. Post-harvest technology Information on post-harvest technology, particularly storage,

13. General agricultural news: requires obtaining general information and news of various agricultural events

14. Crop insurance: Framers require relevant information about crop insurance schemes, the type of damage covered and compensation offered premiums to be paid. etc

\section{ICT Limitations in agriculture}

There are some issues for effective implementation and expansion in agricultural sector. Some of the limitations are:

1. Lack of awareness: Rural peoples are unaware of services offered by ICT and its benefits

2. Coordination: Collective and coordinated mechanism is required between the agency, stakeholders and government to develop a system for agriculture improvement.

3. Easiness of system: Most of the contents are in English which is not easy to use, suitable to needs and abilities of rural population.

4. Connectivity: Lack of reliable internet connectivity and internet access are costlier.

5. Bandwidth: Low bandwidth network can limit effective service to rural area because information concerned to agriculture require intensive use of graphics

6. Information distribution: Effective and efficient use of ICT facilities and services can be done through setting up information kiosks.

7. Private-Public Partnership: Partnerships are required between organizations with different specialties, capacities for ICT implementation in agriculture.

8. Lack of motivation: Rural community is to be motivated for ICT use and its benefits.

9. Schemes and Policies: Majority of development schemes and policies are not focusing on poor community. They are unaware of required information and services which lags improvement agriculture sector.

10. Difficult Terrain and Irregular electricity supply

11. Lack of technicians in the rural sector.

12. Illiterate farmers and stubborn conventional mindsets

13. Heavy expenditure on advocacy

14. Agricultural income depends on the season variation

15. Unpredictable purchase mindset of the peoples

\section{Opportunities and Challenges}

The agricultural sector is facing a challenge to feed increasing population with decline in natural resources such as water, soil fertility, climate change and fertile agricultural lands etc. However, the growing demand provides an opportunity improve the economy for the rural people. It is necessary to set quality standards and regulations for the agricultural related activities. Also new approaches and technology are required to cope with these challenges and to improve the living standards of rural peoples. Farmers are facing many threats e.g. poor soils, drought, erosion and pests, plant disease etc.

ICT can be used to increase the efficiency, productivity and sustainability in agriculture activity because which involves risks and uncertainties. Market access enhances negotiation capacity of the farmers, make decisions about future crops, commodities and the best time and place to sell and buy goods. ICT made a substantial progress and is available, accessible for rural communities. There are still some challenges remain for successful implementation [5]

Proper information of previous initiatives impact is necessary before starting new initiatives. The impact of previous initiative is very difficult to measure because it may not be reported or recorded. To have sustainable ICTs for agriculture initiatives development organizations, governments and the private sector must define indicators and data that validate investments in ICTs and the positive results[5] these may have

1. Content: Most of the contents are in English. The challenging task is to adaptation of content to local needs, languages and contexts. For this purpose appropriate resources and trusted agencies are necessary. Information delivered must match farmers' needs in terms of format and relevance. Delivery of information does not imply effective use of it.

2. Capacity development: We can look the capacity development in three ways: enabling environment, organizational capacity and individual's capacity. Capacities at the individual, organizational and institutional levels need to be strengthened. Without addressing the people's ability to use the facility effectively, just improving access to agricultural information is not sufficient. Other barriers for effective use are illiteracy; limited skills operate complex devices and cultural issues. Capacity development models are to be based on social characteristics, information needs and the function of technology in context. Challenging issue is reach ability of new schemes to millions of formers. Major barrier for most of the people living in most remote area is access cost of ICT facility

3. Gender and diversity: Access and opportunities are not equally distributed among users, Specific policies and procedures are necessary to avoid inequalities and asymmetries access to ICTs facility is limited due to price and persistent inequalities for women, older farmers and people remote areas. Gender inequalities remain a serious issue in the digital economy, as does the gap between urban and rural populations. 
4. Digital Divide: Suitable and proper basic infrastructure and connectivity created a digital divide. It is a multifaceted problem due to ineffective knowledge sharing, lack of human resources, institutional capacity and lack of sensitivity to gender and the diverse needs of different groups. e.g, illiterate and older farmers can't easily adopt to ICTs as they have less skills. Male farmers are adopting more sustainable and productive practice then women. Gender barriers restrict women farmers' capacity to innovate and become more productive.

5. Access and participation: A gender-based digital divide and also digital divide between men and women is more in rural than urban areas, despite the growing number of Internet users. Proper design and implementation based on participatory can reduce the problem in the community.

6. Partnerships: Public-private partnerships are a critical factor in sustainable development at the community level. This can be done with small, local private companies, local organizations and community-based NGOs to provide trusted information and good quality services. Partnership helps to provide various advices and extension services to meet the various needs of farmers

7. Suitable Technology: Finding out the right mix of technologies which suits to local needs and contexts is often a challenge. It is important to know the amount of ICT influence on gender and social dynamics. This provides an opportunity to increase information access rate, but the challenges remain is effective use of technology.

8. Sustainability: Designing the projects for economic, social and environmental sustainability to reach millions of farmers and finding a sustainable model are still challenges. Clear roles and responsibilities are not clarified among stakeholders which hinders the social responsibility.

\section{Benefits of ICT in Agriculture:}

The following are benefits (McNamara, 2009) of agriculture development [6]:

- Agricultural markets becomes efficient and transparent

- Links farmers to urban, regional and global markets

- Improves services and governance for the rural poor

- Promotes farmers in agricultural innovation

- Improves land and natural resource management

- Support to increase rural economy

- Improved efficiency, productivity and sustainability

- Provide information about pest and disease control

- Provides current markets information.

- Strengthen farmer's capacities and representation

- Minimizes social isolation

- Open up new business opportunities.

- Provides weather information

- Improved standard of living

- Better and cheaper access to finance

\section{V.CONCLUSIONS}

Social and economic change is essential agricultural and rural sector .ICT facilities provide information necessary to exchange, buy, produce and sell the product. Intensive training and awareness of ICT and its benefits must be given to the rural community and farmers. More emphasis should be given to the usage of ICT services, to provide relevant information to the farmer. Strong interfaces should be developed at village level. User-friendly software, graphic interfaces and pictorial information will encourage the ICT use. Farmers need to be trained to effectively use the services provided by ICT.

Strategies for implementation and use of ICT in agriculture should be properly formulated. No single institution can alone successfully implement ICT in agriculture and rural areas. Therefore, joint initiation and collaborative plans and schemes among of various stake holders are necessary for successful use of ICT in agriculture.

\section{References}

[1] Jac Stienen with Wietse Bruinsma and Frans Neuman How ICT can make a difference in agricultural livelihoods International Institute for Communication and Development (IICD) The Commonwealth Ministers Reference Book - 2007

[2] Gerard Sylvester“ " Food and Agriculture Organization of the United Nations Regional Office for Asia and the Pacific Bangkok, 2015

[3] Slavoljub Milovanović1 The Role and Potential of Information Technology In Agricultural Improvement Economics of Agriculture 2 UDC: 004.738.5:631 Review article 2014

[4] Published by the Food and Agriculture Organization of the United Nations and International Telecommunication Union Bangkok, EAgriculture Strategy Guide: a summary 2017

[5] World summit on information society turning targets on action 2015 SIS10_ALF_Reporting-C7-E-Agriculture 2015

[6] Sushmita Mukherjee Application of ICT iln Rural Development: Opportunities and Challenges Global Media Journal - Indian Edition/ISSN 2249-5835 Winter Issue / Vol. 2/No.2, December 2011

[7] Ugboh \& E.U. Tibi The Use of Information and Communication Technology (ICT) in Agricultural and Rural Transformation in Delta State. white paper

[8] Shaik. N. Meera, Anita Jhamtani, and. Rao Information and Communication Technology in Agricultural Development: A Comparative Analysis Of Three Projects From India Network Paper No.135January 2004

[9] Monica N. Application of ICT in Agricultural Sector: Women's Perspective Agu International Journal of Soft Computing and Engineering (IJSCE) ISSN: 2231-2307, Volume-2, Issue-6, Jan 2013

[10] https://www.snrd-africa.net/leveraging-ict-to-attract-unemployedyouths-to-agribusinesses-webinar-recording/

[11] Jenny C. Aker Ishita Ghosh Jenna Burrell The promise (and pitfalls) of ICT for agriculture initiatives, The journal of International association of agricultural economics https://doi.org/10.1111/ agec.12301 November 2016

Authors Profile

Ramanna Havinal pursued his Bachelor of Engineering and Master of Engineering degree from Karnataka University, Dharwad, India in 1991, 2000 respectively. He obtained his Ph.D from Jawaharalal Nehru Technological University Anantapur, India in 2017. Presently he is working as Professor in Department of Electronics and Communication Engineering, Maharaja Institute of Technology Mysore, India. He is having more than 28 years of teaching experience and 10 years of research experience .His main research work focuses on Wireless Communications and Wireless Networks, Digital Signal and Image Processing. $\mathrm{He}$ has presented/published more than 20 papers in national, international conferences and Journals. 